einstein

Official Publication of the Instituto Israelita de Ensino e Pesquisa Albert Einstein

ISSN: 1679-4508 | e-ISSN: 2317-6385

\title{
Common origin of the coronary arteries from the right sinus with intramyocardial course of the anterior descent artery
}

Origem anômala comum coronariana do seio direito com trajeto intramiocárdico da artéria descendente anterior

Eduardo Kaiser Ururahy Nunes Fonseca', Lucas de Pádua Gomes de Farias', Bruna Melo Coelho Loureiro', Daniel Giunchetti Strabelli', Nevelton Heringer Filho', Luiz Francisco Rodrigues de Ávila'

${ }^{1}$ Heart Institute, Hospital das Clínicas, Faculdade de Medicina, Universidade de São Paulo, São Paulo, SP, Brazil.

DOI: 10.31744/einstein_journal/2020AI5174
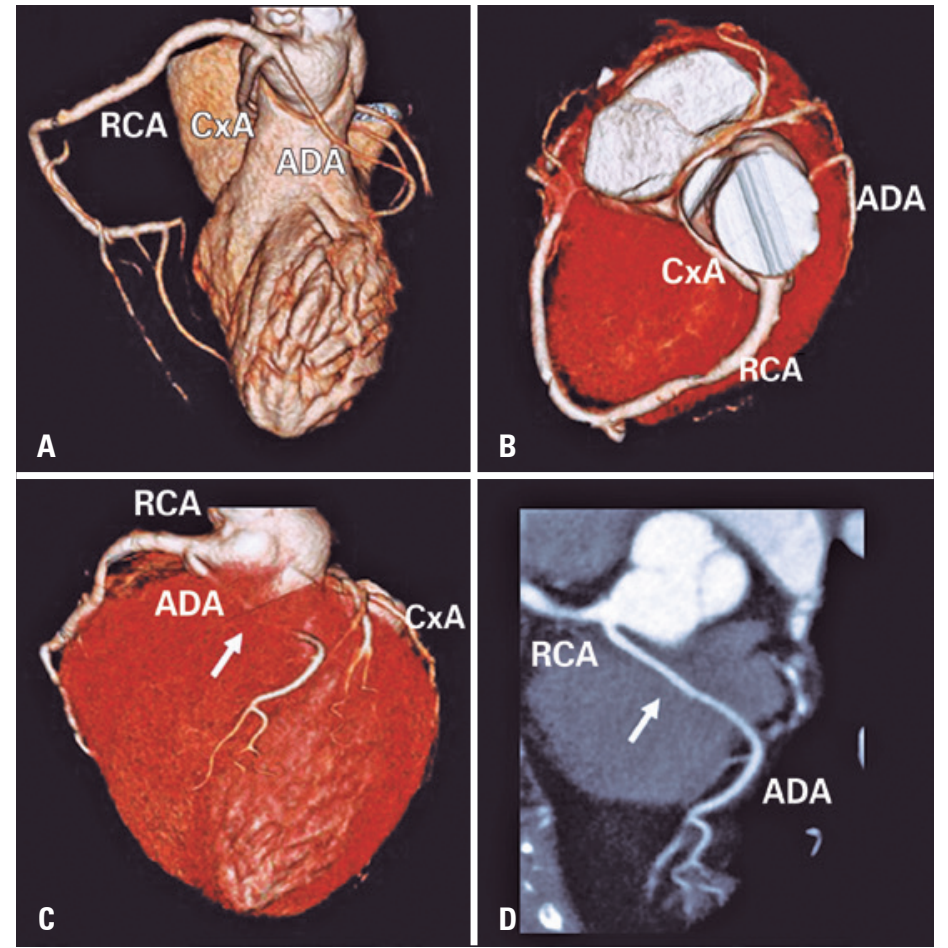

How to cite this article:

Fonseca EK, Farias LP, Loureiro BM, Strabelli DG, Heringer Filho N, Ávila LF. Common origin of the coronary arteries from the right sinus with intramyocardial course of the anterior descent artery. einstein (São Paulo). 2020;18:eAl5174. http://dx.doi.org/10.31744/ einstein journal/2020Al5174

\section{Corresponding author:}

Lucas de Pádua Gomes de Farias

Avenida Dr. Enéas Carvalho de Aguiar,

44 - Cerqueira César

Zip code: 05403-900 - São Paulo, SP, Brazil

Phone: (55 11) 4304-5735

E-mail: lucasdpadua@hotmail.com

\section{Received on:}

May 26, 2019

\section{Accepted on:}

July 1, 2019

\section{Copyright 2019}

\section{(c) By}

This content is licensed

under a Creative Commons

Attribution 4.0 International License. 
Coronary angiotomography showed common origin of coronary arteries through a short common trunk, emerging from the right Valsalva sinus and trifurcating into right coronary artery (RCA), circumflex artery (CxA) and anterior descending artery (ADA). The RCA had habitual course and gives rise to the posterior descending artery (right-dominance). The CxA had a small caliber and retroaortic course without luminal. The ADA had an important angulation in its origin, interarterial course in subvalvar plan and a long proximal intramyocardial segment, where it exhibited a reduction of its diameter, without plaques or parietal changes (Figure 1).

Anomalies of origin and coronary course are relatively common findings, ${ }^{(1)}$ and they can generate ischemia or have no clinical significance. The coronary angiotomography is the goldstandard for anatomy assessment showing coronary courses and their myocardial relationship, ${ }^{(1-6)}$ elegantly depicted by volumetric reconstructions. Among described anomalies, reports about common origin of the coronary arteries by single trunk from the right Valsalva sinus are rare. ${ }^{(2-4)}$ To the best of our knowledge, the association of this set of findings with a long intramyocardial course of the anterior descending artery, determining local vessel compression in ideal conditions of exam (diastolic acquisition with vasodilation and heart rate control) was not previous reported in the published literature, therefore, this is the first case to be reported.

\section{AUTHORS' INFORMATION}

Fonseca EK: http://orcid.org/0000-0002-0233-0041

Farias LP: http://orcid.org/0000-0001-5195-9818

Loureiro BM: http://orcid.org/0000-0002-7270-2664

Strabelli DG: http://orcid.org/0000-0002-0526-5775

Heringer Filho N: http://orcid.org/0000-0002-6139-634X

Ávila LF: http://orcid.org/0000-0003-2282-6084

\section{REFERENCES}

1. Cademartiri F, La Grutta L, Malagò R, Alberghina F, Meijboom WB, Pugliese $\mathrm{F}$, et al. Prevalence of anatomical variants and coronary anomaliesin 543 consecutive patients studied with 64-slice CT coronary angiography. Eur Radiol. 2008;18(4):781-91.

2. Tsioufis K, Latsios G, Tousoulis D, Kallikazaros I, Stefanadis C. Anomalous common origin of all coronary arteries with a common ostium from the left sinus of Valsalva. Int J Cardiol. 2010;139(3): e47-9.

3. Pasaoglu L, Toprak U, Nalbant E, Yagiz G. A rare coronary artery anomaly: origin of all three coronary arteries from the right sinus of valsalva. J Clin Imaging Sci. 2015;5:25.

4. Rao A, Yadu N. Common origin of the coronary arteries: a rare coronary artery anomaly. Med J Armed Forces India. 2016;72(Suppl 1):S189-91.

5. Angelini P. Coronary artery anomalies: an entity in search of an identity. Circulation. 2007;115(10):1296-305. Review.

6. Malagò R, D'Onofrio M, Brunelli S, La Grutta L, Midiri M, Travella D, et al. Anatomical variants and anomalies of the coronary tree studied with MDCT coronary angiography. Radiol Med. 2010;115(5):679-92. Review. 